\title{
A brief analysis of the influencing mechanism of Internet financial behavior: based on congruity perspective
}

\author{
Ruitao Jing \\ School of Information Technology \& Management \\ University of International Business and Economics \\ Beijing, China
}

Keywords: Self-congruity, Functional congruity, External cues, Internet financial

\begin{abstract}
Driven by financial market and information technology, the research on Internet financial management has become a hot topic in this field. Existing research shows that the interaction between consumers and brands facilitates the consumption behavior. By collating the relevant literature in the fields of marketing and psychology, based on the theories of social psychology, this paper initially constructs the theoretical model of Internet financial intention. Then, it provides theoretical basis and suggestions for the further development of the brand image construction of Internet financial management.
\end{abstract}

\section{Introduction}

Relying on the Internet, Internet financial products make great use of technologies such as big data, cloud computing and social network, which reduces the asymmetric information and financial cost, and the users turn to mass consumers. Different consumer groups have different psychological processes on financial decisions and personalized demands are more prominent. In the market of homogeneous Internet financial products, how to meet the personalized needs of investors is the focus of the innovation and development of Internet financial. In other word, products and services are assumed to have personal images, just as people do.

After rapid development, the Internet financial industry has begun to take shape[1]. However, it leads to the mixed quality of online financial products and many problems need to be solved. First, the nature of the product is vague. Some financial management platforms overemphasize the annualized rate of return, while they are vague about the product's nature, rarely mention the direction of investment funds and relevant regulations. Secondly, Market positioning is unclear. At present, the market segmentation of online financial products is divided with the purchase threshold, investment horizon and benefit type as the segmentation criteria, which lacks the understanding of the consumption characteristics of consumer groups and the formulation of targeted marketing strategies. It can be seen that Internet financial products have great room for improvement in strategy formulation.

\section{Literature Review}

\subsection{Internet Financial Behavior}

The research on Internet consumers has touched on e-commerce, insurance products, online group-buying and other aspects. In the existing literature, factors influencing the purchase intention of Internet financial products have been discussed. The existing research on the factors influencing consumers' purchase of Internet financial products can be roughly divided into two aspects.

The first is the process of consumers' acceptance of online financial mode. This kind of research is based on the technology acceptance model (TAM) and its related model (UTAUT), and focuses on the characteristics of the system design itself, such as the influence of factors such as perceived usefulness and perceived ease of use on individual purchase choice[2]. By combining with TAM, 
many foreign scholars found that the brand of the institution, multi-functional service and the improvement of information technology would affect the demand of customers for Internet business when providing related services such as online financing and investment[4].

The second is the acceptance process of consumers under the influence of non-functional value factors such as product characteristics and financial cognition degree. Scholars have tried to analyze it based on other sociological and cognitive theories. By combining the theory of behavior and the neural network analysis method, the demographic characteristics of individual consumers such as gender, age and education were taken into account. Internet financial products are still new. They need to be constantly observed, experienced and learned according to the dynamic environment. It's important to focus on the impact of consumers' psychological cognition on purchase intention. Based on the knowledge of social cognition theory, innovation diffusion theory and other sociological fields, some scholars consider consumer cognitive factors such as product awareness and self-efficacy[7]. They believe that consumers' purchase intention of Internet financial products may be quite different under different cognitive levels.

From the above analysis, it can be seen that many theoretical models are proposed to explain people's attitudes and behaviors towards new information technologies (new products, new phenomena), such as technology acceptance model, planned behavior theory and innovation diffusion theory. Although the constructs and hypothesized relationships of the above theories are different, there is a common feature that individuals' cognition of new technologies (new products or new phenomena) has an important influence on individuals' use behaviors [9].

According to the existing research on the influencing factors of Internet financial behavior, table 1 lists the main influencing factors and the representative literature.

\subsection{Self Concept and Self-congruity}

Ego, a core concept of social psychology, is the way we recognize and feel ourselves. Self-concept is person's overall feeling and comprehensive evaluation of their behaviors, abilities, personality, values and other aspects. Self-concept includes many dimensions. Scholars classify them based on different research perspectives. James (2012) divided self-concept into three types in his classic work "principles of psychology", which are material self, social self and spiritual self. Brewer (1996) divided the self-concept into three levels: individual self, relational self and collective self. Sirgy (1982) divided self-concept into four types: actual self, ideal self, social self and ideal social self.

It is one of the most basic goals of human behavior to protect, maintain and enhance the individual's self-concept. As an important personality trait, self-concept plays a significant role in guiding and predicting individual attitudes and behaviors. Relevant studies show that people purchase products or services for their symbolic meaning as well as the realization of functional value[10]. Grubb and Grathwohl(1967) pointed out that the purchase, display and use of the product can convey the symbolic meaning of the product for individuals to others. Through the symbolic consumption of the product, the individual's self-concept can be promoted.

Based on previous studies, scholars have established the self-congruity theory. Self-congruity represents the conformity between consumers' self-evaluation and product perceived value. In other word, consumers will make comparison and balance between self-concept and product image, and it is an important psychological process to form the recognition of products for consumers.

\subsection{Functional Congruity}

According to the consumer behaviorists, the consumption behavior meet consumers' demand in two aspects, one is to meet their functional needs, the other is image needs. Functional congruity shows consumers' psychological assessment of product characteristics, which is based on the comparison between the actual product features perceived by consumers and the ideal product features in consumers' mind.

The performance characteristics of consumers on product have certain expectations and requirements, from several different dimensions to evaluate products, such as quality, price, safety, easy to use, after-sales service. Each dimension has a weights and given an acceptable range. 
Consumers are satisfied with this performance if they think the product characteristics fall within their acceptable range[12]. The closer the product characteristics are to the ideal level of the consumer, the more satisfied the consumer is with the product characteristics.

However, the current research mainly focuses on the symbolic features of tourism consumption, low-carbon tourism consumption, green product consumption and other consumption, which are rarely seen in the research of Internet finance. This does not mean the construct is unimportant. Because Internet financial has been developing rapidly, it is difficult to have a comprehensive theoretical framework to guide the researchers choose factors. Self- congruity and "functional congruity may be ignored in the research field of Internet financial behavior temporarily in China.

\subsection{Cue theory}

The clue concept was first proposed by Cox (1962), who defined the clue as "information", such as price, color, friends' opinion, taste, feeling, attitude of sales staff. Olson (1972) further expanded Cox's research into internal and external cues. Internal cues are intrinsic attributes of the product. External cues are properties related to the product, but not part of the product object. Internal cues refer to attributes such as material, fragrance and color of commodity entities, while external cues refer to obvious attributes such as brand, packaging and price.

In contrast, consumers tend to use external cues to judge product quality. Internal cues are more important and effective in evaluating products than external cues[14], but external cues are easier to obtain, accessible, and make the process simple. In the process of product quality evaluation and purchase decision making, consumers will judge the internal and external cues on the basis of their existing information. When consumers are unable to grasp the internal clues of the product due to the difficulty in understanding the technical parameters of the product, being unfamiliar with the product or lack of processing motivation, consumers tend to use external cues (price level, brand reputation, product source, etc.) for product quality evaluation and purchase decision.

In the network environment, consumers cannot touch the product personally, making it difficult to obtain and evaluate internal clues. In particular, when consumers do not have motivation or sufficient cognitive ability to consider all product clues, they will automatically use external clues(such as brand, price, user evaluation and place of origin) to make product evaluation and purchase decision. [15]

\section{The Hypothesized Model}

\subsection{External Clues and Self-congruity}

Behavioral plasticity theory holds external clues can not only shape individuals, but also predict individual responses. If consumers cannot make use of the internal clues, the external clues become the consumers' evaluation of online financial products. At present, there is no integrated research on the relationship between external clues and self-congruity of Internet financial products, but scholars have studied the relationship between brand image, product reputation, service commitment, social influence, price and self-congruity respectively. Srinivasan (2005) believe that availability is the main factor limiting brand consumption. High availability provides more channels to evaluate the brand image, and gives consumers more opportunities to use the brand reflection and improve themselves to achieve self-consistency. Based on the above analysis, this study proposes the following hypothesis:

H1: external cues have significant positive effects on self- congruity;

\subsection{External Clues and Functional Congruity}

Functional consistency refers to the degree of conformity between the product's functional attributes and consumers' expected attributes. According to the clue theory, in the process of product evaluation and purchase decision making, consumers will sort out and judge the internal and external clues of the products they contacted with on the basis of existing information, so as to form product evaluation. 
However, due to the asymmetric information, consumers tend to use the external cues (price level, brand image, product reputation, etc.) to make product evaluation and purchase decisions. For Internet financial products, as consumers have difficulty in obtaining information about their internal operation and capital flow, the process is made easier by using external clues (product reputation, brand image, purchase threshold, rate of return, liquidity, etc.). Based on the above analysis, this study proposes the following hypothesis:

H2: external clues have significant positive effects on functional congruity;

\subsection{Self-congruity and Purchase Intention}

Sirgy (1997) refer to the process of improving consumers' self-image by purchasing products that are identical or similar to their own characteristics as self-congruity. Through product consumption, consumers can build, present and strengthen their self-identity. According to the theory of self-presentation and impression management, the behavior of people in order to create, modify and maintain other people's impression of themselves is conducive to social interaction, helping to build the desired identity of individuals and making themselves more comfortable psychologically. With the improvement of financial awareness among young people, especially college students, Internet financial management is not only to gain profits, but also to convey their life attitudes, thinking modes and action ability to the outside world, so as to urge consumers to strengthen their self-concept by purchasing and using online financial products. Based on the above analysis, this study proposes the following hypothesis:

H3: self-congruity has a significant positive effect on purchase intention;

\subsection{Functional Congruity and Purchase Intention}

Relevant studies show that people purchase products or services for their symbolic meaning as well as the realization of functional value. Consumers often have certain expectations on the performance of products (such as quality, price, after-sales service, etc.). Many studies have proved that functional congruity can predict consumer behavior, and sometimes it has a stronger influence on consumer behavior than self-concept consistency. For consumers, the financial characteristics of financial products directly affect the experience and return of Internet financial management. Financial products with high yield, security or liquidity can effectively improve consumers' financial experience and satisfaction, and make consumers agree with the products. The financial characteristics of Internet financial products have become the key factor of whether consumers conduct financial management. Based on the above analysis, this study proposes the following hypothesis:

H4: functional congruity has a significant positive effect on purchase intention.

\section{Application Prospect and Conclusion}

Product scenarios. By combining users' financial demands and different life scenes, users' attention is transferred from self-income to other financial information based on life demands. This can further popularize Internet financing and attract more groups to participate in it.

Product interaction. In recent years, the mobile financial industry has been attracting customers and attracting customers. User experience is an important factor that determines whether the financial platform can survive in the long term and stick to users. It enhances the interactivity, interest and study of financial management, and improves the connotation and boundary of financial service.

Visualize the product. This creates a deep sense of user identity, which fosters user habits and ultimately leads to loyal customers. For young people, financial products can start from the image building and self-image display to highlight the social psychology of young people.

This model, which is the theoretical basis of social psychology, takes into account the external cues (such as price, product image), self-consistency and functional consistency to evaluate the willingness of Internet financial management that affects consumers. In the research factors, external cues, self-consistency, functional consistency and purchase intention are all positively correlated. 
However, the empirical method model has not been adopted in this paper, which will be discussed in the next research.

\section{References}

[1] Jun Wang, Guofeng Zhao, Analysis on the development and supervision of Internet finance in China, Reform and strategy, vol.3, pp. 72-75, 2017.

[2] Baoguo Zhao, Yinghui Cheng, Research on factors influencing the acceptance behavior of individual users of online investment and financial management, Research on financial issues, vol.8, pp. 50-55, 2016.

[3] Qiu Junping, Yang Qiang, Guo Lilin, Study on factors influencing the use of Internet financial products, Intelligence journal, vol.34, pp. 179-184, 2015.

[4] Ming-Chi Lee, Factors influencing the adoption of internet banking : An integration of TAM and TPB with perceived risk and perceived benefit, Electronic Commerce Research and Applications, vol.8, pp. 130-141, 2009.

[5] Kenneth C.C. Yang, Exploring factors affecting the adoption of mobile commerce in Singapore, Telematics and Informatics, vol.22, pp.257-277,2005.

[6] Gefen D, Karaharma E, Straub D W, Trust and TAM in Online Shopping: an Integrated Model, MIS Quarterly, vol.27, pp. 51-90,2003.

[7] Xu Xiaoyang, Lu Minghui, Research on the buying behavior of Internet financial products based on social cognition theory, Soft science, vol.31, pp. 108-113,2007.

[8] Liu Dianwei, Empirical study on the key influencing factors of consumer online shopping decision-making - based on innovation diffusion theory, Science and technology management research, vol.5, pp. 175-179, 2014.

[9] Ritu Agarwal, Elena Karahanna, Time Flies When You're Having Fun: Cognitive Absorption and Beliefs about Information Technology Usage, MIS Quarterly, vol.24, pp. 665-694, 2000.

[10]Grubb E L, Grathwohl H L, Consumer self-concept, symbolism, and market behavior: A theoretical approach, Journal of Marketing, vol.31, pp. 22-27, 1967.

[11]Belk R W, Possessions and the extended self, Journal of Consumer Research, vol.15, pp. 139-168, 1988.

[12] Sirgy M J \& Su C, Destination image, self- congruity, and travel behavior: Toward an integrative model, Journal of Travel Research, vol.38, pp. 340-352, 2000.

[13] Sirgy M J, Grewal D, Mangleburg T F. Assessing the Predictive Validity of Two Methods of Measuring Self-image Congruence, Journal of the Academy of Marketing Science, vol.25, pp. 229-241, 1997.

[14]KL Ailawadi, SA Neslin, K Gedenk, Pursuing the Value-Conscious Consumer: Store Brands Versus National Brand Promotions, Journal of Marketing, vol.65, pp. 71-89, 2001.

[15] Szybillo J. J, Jacoby J, intrinsic versus extrinsic cues as determinants of perceived product quality, Journal of Applied Psychology, vol.59, pp. 74-78, 1974. 